\title{
The response of the Ekströmisen (Antarctica) grounding zone to tidal forcing
}

\author{
Björn Riedel, ${ }^{1}$ Uwe Nixdorf, ${ }^{2}$ Mighael Heinert, ${ }^{1}$ Alfons Eckstaller, ${ }^{2}$ Christoph Mayer ${ }^{2}$ \\ ${ }^{1}$ Institut für Geodäsie und Photogrammetrie, Technische Universität Braunschweig, D-38106 Braunschweig, Germany \\ ${ }^{2}$ Alfred Wegener Institute for Polar and Marine Research, P.O. Box 120161, , D-27515 Bremerhaven, Germany
}

\begin{abstract}
During the austral summer 1996-97 an extensive field program with geophysical and geodetic observations was carried out in the vicinity of the grounding line of Ekströmisen, Dronning Maud Land, Antarctica. The main emphasis of the joint program was placed on continuous observations of the horizontal as well as the vertical component of the ice displacement across the grounding zone. Data-processing methods for the in parts discontinuous time series and the vertical displacements in the area of the grounding zone are described, and first results presented, with the focus on the influence of the ocean tides on grounded ice. Tidal-induced deflections with amplitudes of up to $0.15 \mathrm{~m}$ were recorded at a station on grounded ice $1 \mathrm{~km}$ from the grounding line.
\end{abstract}

\section{INTRODUCTION}

Ice shelves play an important role in the dynamics and possibly also in the stability of the Antarctic ice sheet. In order to be able to estimate the reaction of the ice sheet to sea-level change, it is necessary to understand the dynamical processes in the grounding zone. For this purpose a numerical icesheet-ice-shelf model of the grounding zone was applied to field data for Ekströmisen, Dronning Maud Land, Antarctica (Mayer, 1996). The grounding zone of an ice shelf is often characterized by a change of surface slope from a steep, undulated surface of the grounded ice to a gently sloping surface of the floating ice shelf. Details are described by Vaughan (1994). Transition processes from shear-stress-dominated dynamics to a longitudinal stress regime characterize the ice in the area. Another characteristic feature is the onset of ablation processes at the ice-ocean interface right at the grounding line.

In order to obtain input data for future elasto-mechanical modelling, field data have been collected at the southern grounding line of Ekströmisen. The main emphasis of the field program was placed on collecting continuous observations of the horizontal as well as the vertical component of the ice displacement and their lateral variations across the grounding zone. The first modelling approach uses a simple elastic-beam model (Holdsworth 1969) to obtain an approximation for tidal deflection dependent on Young's modulus.

\section{FIELDWORK}

During the austral summer 1996-97 an extensive field program was carried out with geophysical observations (reflection seismics, gravity, radio-echo sounding) and geodetic terrestrial and satellite measurements across the grounding line of Ekströmisen (Nixdorf 1997), one of the smaller ice shelves in northern Dronning Maud Land. The expedition started at the German wintering base Neumayer situated in the northern part of the ice shelf close to Atka Bay $\left(70^{\circ} 36^{\prime} \mathrm{S}\right.$, $\left.08^{\circ} 15^{\prime} \mathrm{W}\right)$. The area of investigation is located $120 \mathrm{~km}$ south of the base.

We measured the response of the ice body to the ocean tides at different locations with different sensor types: on the ice shelf $5 \mathrm{~km}$ from the grounding line, at the grounding line and on the grounded ice at $0.5,1,2$ and $3 \mathrm{~km}$ from the grounding line (Fig. 1).

To calculate the tidal deflection, data from two gravity meters (LaCoste Romberg gravity meters, G-type) and two tiltmeters (Tilt Ltd, Electrolevel type) with external data loggers were used. These instruments were buried in snow pits at the sites A0, GL0, km05, kml and km2. The recorded signals of the instruments are mainly due to the vertical displacement

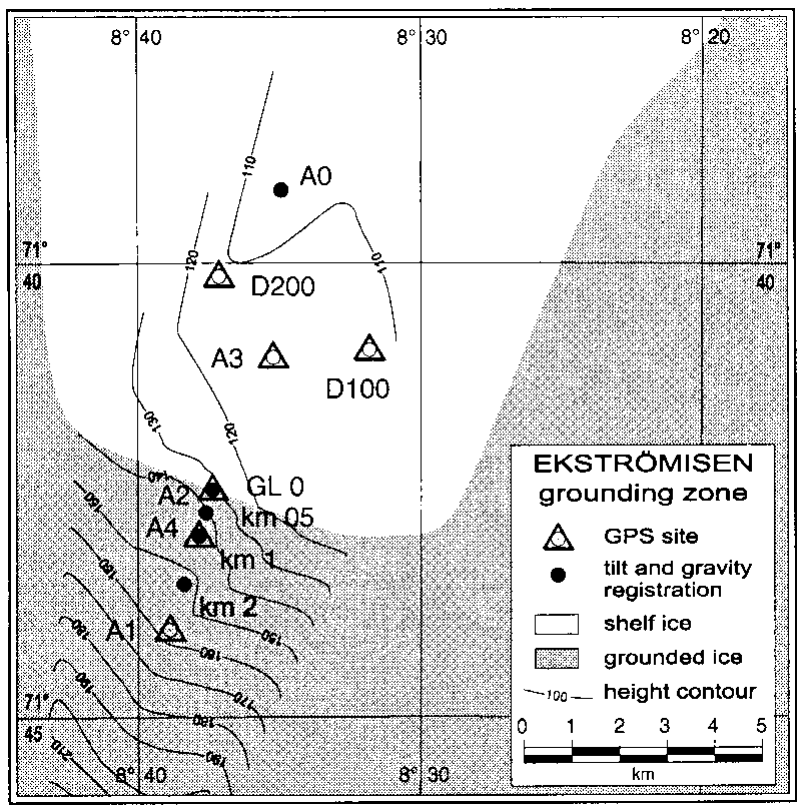

Fig. 1. The southern Ekströmisen grounding zone with the sites for continuous data. 
of the ice body under the influence of both ocean and earth tides. The length of the recorded time series is 5-13 days.

As reference data for the ocean tide signal we used the gravity time series of the Neumayer observatory. The tidal deflection influencing the gravity recording at Neumayer is primarily caused by the local sea tides (Tezkan and Yaramanci, 1993).

In addition, six global positioning system (GPS) receivers (Trimble 4000 SSE) collected data in two different types of arrays. To determine the absolute ice movement, differential GPS was used in connection with a reference station on solid rock. Continuous strain observations were recorded in a second triangular array. The GPS observations lasted up to 16 days with only short interruptions. Through kinematic data-processing, three-dimensional coordinates were derived for every recorded time epoch.

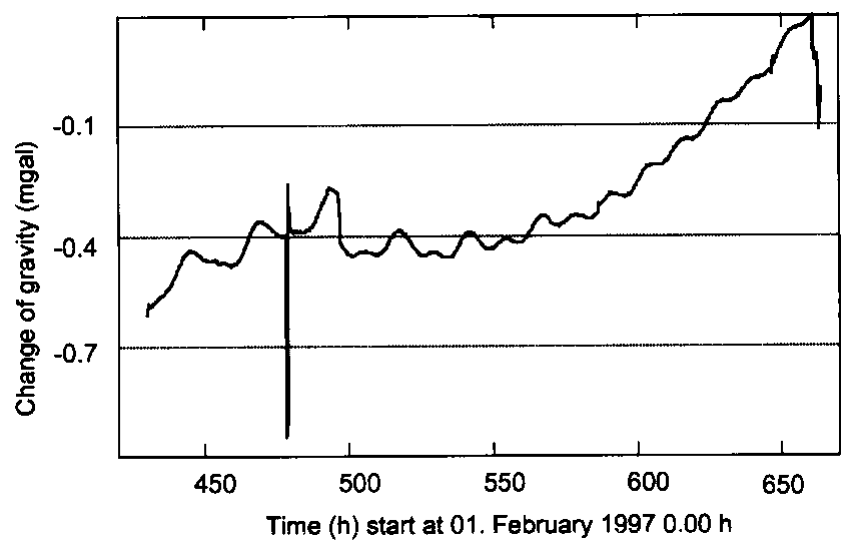

Fig. 2. Raw field data from gravity recordings at position $\mathrm{km} 2$.

\section{DATA PROCESSING}

Firstly, the recorded gravity and tiltmeter data had to be calibrated. Data gaps occurred due to battery failure and during the downloading of the data. To fill these gaps the Melchior procedure was adapted (Kobarg, 1988), allowing further analysis on continuous time series. Then outliers had to be detected and removed. Snowdrift in the snow pits caused a change in the levelling of the instruments, resulting in an instrumental drift. These trends and the high-frequency noise were removed by bandpass filtering. Figure 2 shows a typical raw dataset for position $\mathrm{km} 2$.

These procedures resulted in continuous time series of 5-10 days for the gravimeter and tiltmeter data.

The processing of the GPS data started with static processing of position $\mathrm{Al}$ in relation to the reference field station in the Kottas mountains (Heimefrontfjella; $74^{\circ} 18^{\prime} \mathrm{S}, 9^{\circ} 45^{\prime} \mathrm{W}$; $1420 \mathrm{~m}$ a.s.l.). This reference station was $3 \mathrm{~km}$ south of the grounding line on grounded ice. The daily coordinate solutions for $\mathrm{Al}$ were used as the local base-station data, and the kinematic post-processing of the other GPS stations was carried out in relation to position Al. The flow velocity of position $\mathrm{Al}$ was addressed as a trend effect. All following processing steps were similar to the processing of the tiltmeter and gravity data (e.g. the filling of data gaps and removal of outliers).

The kinematic data-processing for all GPS stations provided coordinates for each antenna phase center in the three

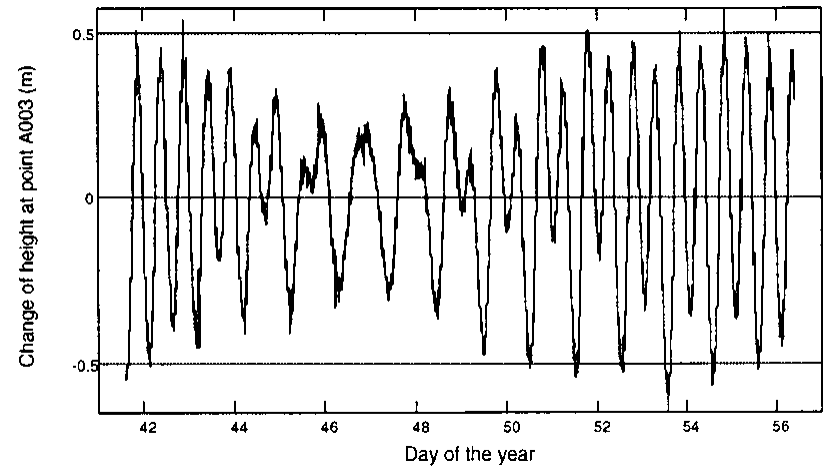

Fig. 3. Time series for the vertical movement of the antenna phase center for $A 3$.

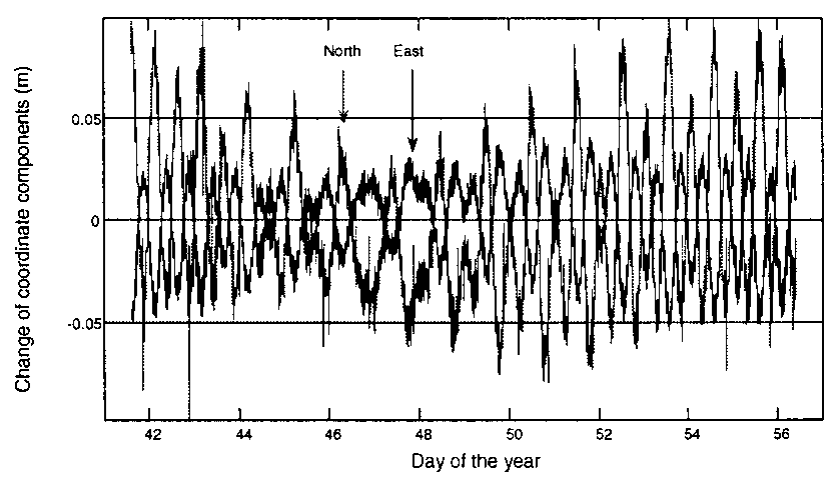

Fig. 4. Time series for the horizontal movement of the antenna phase center for $A 3$.

coordinate components. Figures 3 and 4 show the continuous time series for the three-dimensional movements of the 16 day dataset for station A3, situated on the ice shelf $3 \mathrm{~km}$ downstream from the grounding line. The tidal deflection shows maximum amplitudes of $\pm 0.50 \mathrm{~m}$ for station A3.

According to Figures 3 and 4, it is obvious that tidal deflection in the case of high tide leads to a horizontal movement of the antenna towards the south. Low tide causes horizontal movement to the north. The third coordinate component also shows a tidally induced east-west movement. There is a high correlation between the vertical deflection and the horizontal movement during the tidal cycle. The same pattern was derived for station A2, located

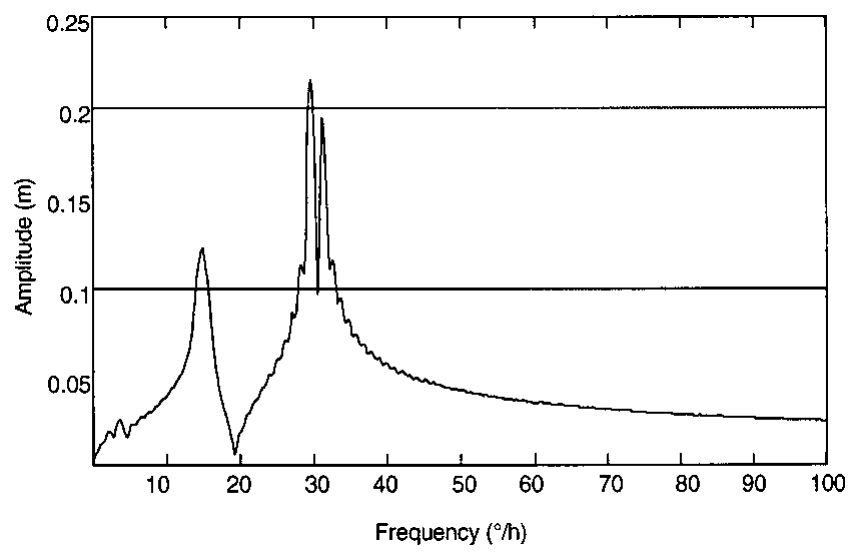

Fig. 5. Tidal spectrum for position A2. 


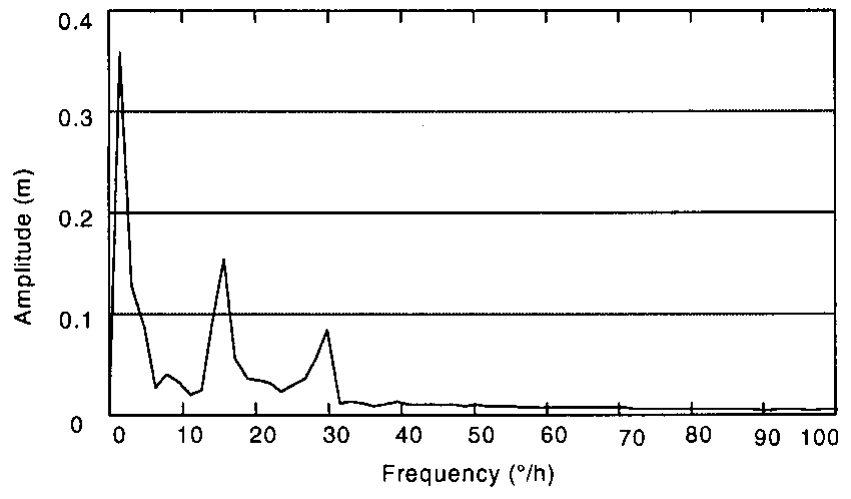

Fig. 6. Tidal spectrum for position $\mathrm{km} 2$.

on the grounding line, with a maximum tidal deflection of $\pm 0.15 \mathrm{~m}$ (Riedel, 1998). The shorter time series of 8 days for stations D100 and D200 yielded similar results. For position A4 we were unable to derive any tidal displacement from the processing of the kinematic GPS data.

The fast Fourier transform (FFT) was applied to the GPS, gravity and tiltmeter time series in order to derive amplitudes, frequencies and the phase of the ocean tides.

It was possible to derive the diurnal tides $\mathrm{Kl}$ and $\mathrm{O} 1$ and the semi-diurnal tides M2 and S2 for position A2, as well as for the other GPS sites, with the 16 day GPS dataset (Fig. 5). The FFTs of the shorter time series show fewer details. For instance, the 8 day series of the position $\mathrm{km} 2$ gravity data resolves one diurnal and one half-day tidal signal (Fig. 6).

The tidal signal for position $\mathrm{km} 2$ on grounded ice, $2 \mathrm{~km}$ south of the grounding line, has an amplitude that is as big as the signal amplitude that can be calculated for the Earth tides at this station with the program ETGTAB (Timmen and Wenzel, 1995). This implies that the observations in this snow pit were caused solely by the influence of the Earth tides on the grounded ice body.

Table 1. Optimized amplitudes of the main ocean tidal wave

\begin{tabular}{lccccl}
\hline Site/wave & O1 & $K 1$ & M2 & S2 & Derived from \\
& $\mathrm{m}$ & $\mathrm{m}$ & $\mathrm{m}$ & $\mathrm{m}$ & \\
& & & & & \\
\hline A2 & 0.011 & 0.010 & 0.019 & 0.022 & $\mathrm{GPS}$ \\
$\mathrm{A} 3$ & 0.120 & 0.109 & 0.224 & 0.168 & $\mathrm{GPS}$ \\
D100 & 0.152 & 0.125 & 0.242 & 0.272 & GPS \\
D200 & 0.118 & 0.105 & 0.195 & 0.211 & GPS \\
A0 & 0.212 & 0.193 & 0.395 & 0.297 & Gravity observations \\
GL0 & 0.045 & 0.041 & 0.085 & 0.064 & Gravity observations \\
km05 & 0.060 & 0.055 & 0.113 & 0.085 & Gravity observations \\
km1 & 0.040 & 0.037 & 0.076 & 0.057 & Gravity observations \\
\end{tabular}

\section{PRELIMINARY RESULTS}

Because the different tidal waves are well known from astronomical observations, the results of the FFT could be optimized by the application of a conditioned least-squares fit, resulting in a kind of harmonic analysis. The result of this analysis is the splitting of the signal into ocean and body tides. Table 1 shows the signal of the ocean tides for the different stations on the ice body. The results of this analysis are preliminary, because there is an unsolved difference

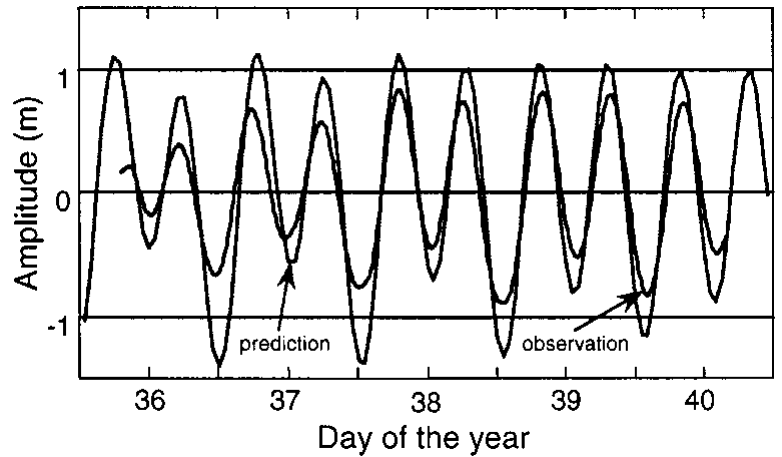

Fig. 7. Observed and predicted data for station AO.

between amplitudes from the GPS and gravity measurements for station A2. This difference could be accounted for by the differences in the length of the time series or by the difference between the geometrical displacement observed by the GPS and the tidally influenced water-mass movement between the bottom of the ice body and the bedrock in the grounding zone. An observed gravity signal at this position may not be caused by vertical displacement of an identical amplitude.

The data so far show a clear influence of the ocean tides on the ice movement at least up to $1 \mathrm{~km}$ south of the grounding line on grounded ice.

A comparison of the observed data at station A0 with the predicted data from a modified ocean tidal model for the Weddell Sea (Fig. 7) shows that the observed values are only $75 \%$ of the predicted values (Robertson and others, 1998). This means that tidal information from models cannot always be used to exactly describe the vertical tidal deflection of the grounding zone.

The method of analysis described enables us to calculate time series for every station and any period, especially for positions where we had no instruments or for time intervals where we had data gaps. These time series of tidal amplitudes, together with the tilt values, will be used for future mechanical modelling.

An example of differences between observed and modelled tiltmeter data is shown in Figure 8. In the model all significant tidal parameters have been considered. The maximum differences between modelled and observed tiltmeter data are $<3 \mu \mathrm{rad}$. This means that modelled and observed values are in very good agreement.

\section{GONGLUSION AND OUTLOOK}

The present study shows that it is possible to estimate the

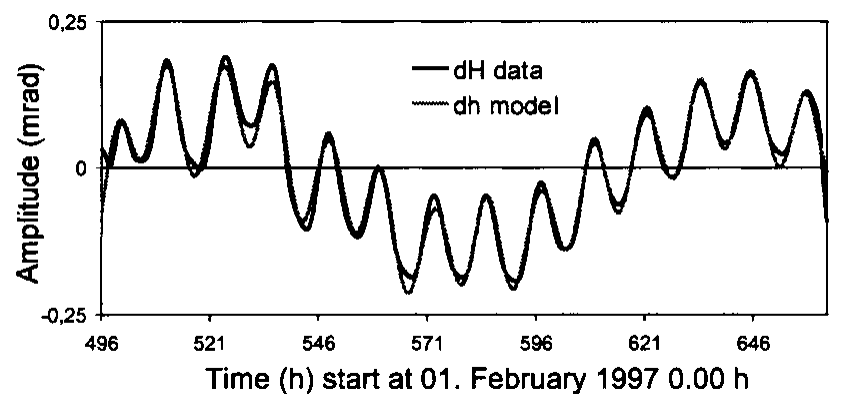

Fig. 8. Differences between modelled and observed tiltmeter data. 
range of the ocean tides on the ice body and to derive the tidal deflection. This is also true for grounded ice. Using this information and other collected data, such as ice thickness and surface elevation, it is possible to build up an elasto-mechanical finite-element model for the Ekströmisen grounding zone. The combination of the time series of tidal amplitudes, the tilt values and the GPS positions results in a varying geometry of the ice body, i.e. the geometry vector. This derived geometry vector comprises the main input parameter for mechanical modelling using a finite-element method.

Further investigations need to be carried out with the aim of studying variations of Young's modulus in relation to the ice thickness, ice-surface topography and tidal deflections.

\section{AGKNOWLEDGEMENTS}

The authors wish to express their gratitude to the Deutsche Forschungsgemeinschaft for financial support through grant Ri 766/2. We thank L. Erofeeva and L. Padman for the prediction of ocean tidal data for Ekströmisen, and an anonymous reviewer and K. Keller for their comments and suggestions which improved the manuscript.

\section{REFERENCES}

Holdsworth, G. 1969. Flexure of a floating ice tongue. F. Glaciol., 8(54), 385-397. Kobarg, W. 1988. Die gezeitenbedingte Dynamik des Ekström-Schelfeises, Antarktis. Ber. Polarforsch. 50.

Mayer, C. 1996. Numerische Modellierung der Übergangszone zwischen Eisschild und Schelfeis. Ber. Polarforsch. 214.

Nixdorf, U., A. Lambrecht and D. Steinhage. 1997. Geophysical-glaciological studies in the grounding zone area of the Ekström Ice Shelf (EIS). In Oerter, H., comp. Filchner-Ronne Ice Shelf Programme (FRISP). Report No. 11. Bremerhaven, Alfred Wegener Institute for Polar and Marine Research, 51-54.

Riedel, B. and M. Heinert. 1998. First results of GPS array observations in the grounding zone of Ekstroem Ice Shelf. In Oerter, H., comp. FilchnerRonne Ice Shelf Programme (FRISP). Report No. 12. Bremerhaven, Alfred Wegener Institute for Polar and Marine Research, 74-76.

Robertson, R., L. Padman and G. D. Egbert. 1998. Tides in the Weddell Sea. In Jacobs, S. S. and R. F. Weiss, eds. Ocean, ice and atmosphere: interactions at the Antarctic continental margin. Washington, DC, American Geophysical Union, 341-369. (Antarctic Research Series 75.)

Tezkan, B. and U. Yaramanci. 1993. The effect of sea tides on gravity tidal observations on the Antarctic Ekström ice shelf. Geophys. F. Int., 114(3), $561-568$.

Timmen, L. and H.-G. Wenzel. 1995. Worldwide synthetic gravity tide parameters. In Sünkel, H., ed. Gravity and geoid. Berlin, International Association of Geodesy, 92-101.

Vaughan, D. G. 1994. Investigating tidal flexure on an ice shelf using kinematic GPS. Ann. Glaciol., 20, 372-376. 